\title{
Is it possible to revert doctor-patient relationship deterioration?
}

In recent decades, medicine has developed promising advances in the diagnosis, treatment and prognosis of serious diseases. Nevertheless, this process is usually overwhelming and thus faces multiple obstacles since it is evident that continuous progress cannot be beneficial, and it is detrimental to the scientific, ethical and economic aspects.

It seems that in the context of such commodified care, the main problems are perceived as if they were only the crisis of management. Consequently, medical language is more and more dominated by the market, and we constantly hear the words costs, deductions, copayments, customers, etc.

Therefore, we are increasingly observing that medicine is losing the essential purposes that are part of art, while science is growing. Hence the question often arises, are utmost knowledge and high financial resources critical to solve most patients' problems? The answer is no, since most health disorders can be solved through adequate clinical practice without the need to resorting to ancillary tests or modern technology. However, to do what is necessary from a rational stand point, we must have good clinical judgment and, at all times, accept uncertainty, essential to perform adequate medical practice.

One of the goals of medicine is based on the following concepts: "Despite all scientific progress, human beings will continue getting sick and dying. Pain and suffering will go on being part of human nature. Judicious medicine will balance its advances against disease, but with a lasting sense that its main role is to help people live as healthily as they can for as long possible, within the limits of a finite lifespan". ${ }^{1}$

Art, whatever its form, comes from the depths of human beings as a manifestation of their desires and feelings that, in general, are oriented to creating something good, beautiful, pleasant... We could define it as "The ability or capacity to do something through knowledge and practice".

Medical art, unlike other art forms, allows us to be close to the patient, aiming at the restoration of a natural state, through science, but mainly through support, affection, consolation, compassion. ${ }^{2}$ Science wants to find something while art wants to perform something.

The doctor-patient relationship is inherent to art and it is, undoubtedly, one of the crucial aspects of our profession. It is noteworthy that the main desire of patients and parents is to receive the medical care that will allow them to develop confidence in their doctors. As human beings, we know that trust is essential in all our relationships and therefore it cannot be absent from medical practice.

Patients' views of the good doctor are varied. In a systematic review on patient priorities for general practice care, the first one was "humaneness", then: competence, time for care and patients' involvement in decisions. ${ }^{3}$ Another study showed that the main priority was on having a "doctor who listens and does not hurry me", ${ }^{4}$ and in another patients' first choice on the doctor's interpersonal skills was: "trust". ${ }^{5}$

As pediatricians, we should understand some aspects of our encounters with parents and adolescents so as to foster a proper relationship. Even though many may assume it, sympathy is not at all enough. We need to nurture empathy, which means to be able to interpret what parents tell us as if we were "inside" them. It involves much more than just addressing the problem, it requires understanding the dilemma and pain they are going through.

This requires to listen and not to hurry, to unveil their anxieties and fears, and to keep our focus on the best interests of the child and their family. Moreover, we need to acknowledge parents' cultural limitations and talk to them in a plain language to help them express what they feel. There are about thirty thousand words we usually use and that our patients are unaware of. ${ }^{6}$

We have to make our best effort to avoid misleading communication. Otherwise, it may happen what Abraham Maslow, a well-known American psychologist and one of the founders of humanistic psychology, accurately and quite humorously said: "If you only have a hammer, you tend to see every problem as a nail".

For us, doctors, communication is usually not part of our training, either at university or at subsequent training, which is unfortunate since communication is much more important than many things we were taught and which were of no use.

I must emphasize that in my experience, I owe everything I learned about the relationship with parents to Dr. Gianantonio, the ever-present teacher who was our boss for almost 20 years and whose legacy was leading by example, which is, 
in my opinion, the best and longer-lasting way of teaching.

In our weak and limited medical education we not only lacked general concepts of communication skills, but also other aspects of them, such as the use of the word, essential for communication. More often than not, we come across pediatricians who are very willing to properly communicate with parents but who use complex words that are not understood, particularly when they have to face hard situations regarding children's health, or more noticeable, when they face parents whose child is going to die. They cannot accept the inevitable fatal outcome of that child who is their patient. This brings about a decrease in the number of visits with the parents and the child, and they slowly grow apart until they stop coming, precisely when the family needs it most. One way to help reverse this attitude is the essential concept that words, apart from being a bridge for human relations, also convey emotions. We should nurture this crucial aspect in our profession since it has a huge significance in communication and can help us overcome those difficult moments.

It is common to see doctors hiding emotions at work because they assume it is not right to make them evident. This is a serious mistake because feelings are inevitably present in every human action, and it is pointless to try to suppress them in front of patients. ${ }^{7}$

Nowadays there is a major crisis of confidence in patients concerning their relationship with doctors; and as stated above, lack of confidence destroys any human relationship. Undoubtedly, we are the only ones to be blamed for that, by being unaware that distrust is a consequence, to a great extent, of poor communication. ${ }^{6}$

The doctor-patient relationship is crosssectional, and as such, it should be appropriate in all instances of our practice, whether dealing with mothers, before and after giving birth, or dealing with parents of hospitalized children, in emergency rooms and at our offices. As I pointed out, communication has to be carefully managed when children are very sick and likewise, before discharge, when poor information can lead to potentially fatal mistakes.

Last, I want to emphasize some aspects as follows. It is imperative that we take a critical view of our behavior when interacting with parents and patients; this will allow us to accept the great significance it has, and that we should do so with the essential attributes of our profession: support, consolation, empathy, caring and concern.

There is no doubt that being good doctors involves understanding that proper communication is an ethical demand, because only in this way, in our practice, we will be able to be on the side of science, human judgment and humanistic values.

José M. Ceriani Cernadas Editor

http:/ / dx.doi.org/10.5546/aap.2016.eng.290

1. The goals of medicine. Setting new priorities. Hastings Cent Rep 1996;26(6):S1-27.

2. Jaspers K. La práctica médica en la era tecnológica. Barcelona: Gedisa; 1988.

3. Wensing M, Jung HP, Mainz J, Olesen F, et al. A systematic review of the literature on patient priorities for general practice care. Part 1: Description of the research domain. Soc Sci Med 1998;47(10):1573-88.

4. Carroll L, Sullivan FM, Colledge M. Good health care: patient and professional perspectives. Br J Gen Pract 1998; 48(433):1507-8.

5. Mechanic D, Meyer S. Concepts of trust among patients with serious illness. Soc Sci Med 2000;51(5):657-68.

6. Gil Deza E. La palabra médica. Buenos Aires: IntraMed; 2015.

7. Evans RG. Patient centred medicine: reason, emotion, and human spirit? Some philosophical reflections on being with patients. Med Humanit 2003;29(1):8-14. 